\title{
The Study of the Preparation of Catalysts for Carbonyl Sulfide Hydrolysis under Moderate Temperature
}

\author{
Yikun Xu, Shangguan Ju*, Zexing Wang, Yanxia Liu \\ Key Laboratory of Coal Science and Technology of Shanxi Province and Ministry of Education, Taiyuan University of \\ Technology, Taiyuan, China \\ Email: *shanggj62@163.com
}

How to cite this paper: Xu, Y.K., Ju, S.G., Wang, Z.X. and Liu, Y.X. (2018) The Study of the Preparation of Catalysts for Carbonyl Sulfide Hydrolysis under Moderate Temperature. Journal of Materials Science and Chemical Engineering, 6, 31-38.

https://doi.org/10.4236/msce.2018.64005

Received: November 9, 2017

Accepted: April 5, 2018

Published: April 12, 2018

\begin{abstract}
Multifunctional composite catalyst for carbonyl sulfide hydrolysis under moderate temperature was prepared by impregnation method. The hydrolysis and deoxidization ability of the prepared catalyst was investigated in a fixed bed reactor. It was found that deoxidization ability of the prepared catalyst was raised by the increase of the content of potassium loading catalyst and reaction temperature. And the concentration of $\mathrm{H}_{2} \mathrm{~S}$ had no effect on deoxidization while COS improved the deoxidization ratio. And deoxidization rates were nearly scaled up with concentration of $\mathrm{H}_{2}$. The hydrolysis ability was decreased by the decrease of the surface basicity.
\end{abstract}

\section{Keywords}

Carbonyl Sulfide Hydrolysis, Deoxidization, Catalyst, Moderate Temperature

\section{Introduction}

In the process of coal coking, through a series of complex physical and chemical reactions, coal was generated into the coke oven gas eventually. Coke oven gas contains a lot of sulfide, hydrogen chloride, hydrogen fluoride and other gases, and trace amount of these compounds can result in the deactivation of the following catalysts and lead to corrosion of the following reaction equipment [1]-[6]. The amount of sulfur in the gas must be decreased to a standardized scope. So the sulfide in coke oven gas must be removed before used. Coke oven gas contains not only hydrogen sulfide $\left(\mathrm{H}_{2} \mathrm{~S}\right)$ but also other sulfurous gases including carbonyl sulfide (COS). In comparison to $\mathrm{H}_{2} \mathrm{~S}$, $\mathrm{COS}$ is more difficult to remove due to its low reactivity in many desulfurizers. Therefore, the formation 
of COS in coke oven gas will reduce the coke oven gas desulfurization efficiency. Many studies of COS removal by sorption, catalytic hydrolysis and hydrogenation conversion have been reported in order to overcome this limitation [7] [8] [9] [10]. An alternative technology has been used for the removal of COS, and this is based on the formation of $\mathrm{H}_{2} \mathrm{~S}$ by hydrolysis: $\mathrm{COS}+\mathrm{H}_{2} \mathrm{O}=\mathrm{H}_{2} \mathrm{~S}+\mathrm{CO}_{2}$.

Liu et al. [11] studied the heterogeneous reaction of COS on metal oxides. The results showed that the activity series for heterogeneous hydrolysis of COS decreased in the following sequence: $\mathrm{Al}_{2} \mathrm{O}_{3}>\mathrm{CaO}>\mathrm{MgO}>\mathrm{TiO}_{2}>\mathrm{ZnO}>\mathrm{Fe}_{2} \mathrm{O}_{3}>$ $\mathrm{SiO}_{2}$. The specific surface area and surface basicity of these oxides have great effect on the catalytic activity. Shangguan et al. [12] prepared the catalyst containing $\mathrm{Al}_{2} \mathrm{O}_{3}$ and $\mathrm{K}_{2} \mathrm{CO}_{3}$ at low temperature and an improved desulfurization performance was reported. Loading $\mathrm{K}_{2} \mathrm{CO}_{3}$ can increase the basicity of catalyst, which increases the COS hydrolysis ability. However, some desulfurization process must be carried out under intermediate temperatures, and in this temperature, $\mathrm{Al}_{2} \mathrm{O}_{3}$ is easy to be sulfated which will decrease the catalytic activity. Liujun et al. [13] thought reduce catalytic activity was due to oxygen existed in gas. The oxygen can make $\mathrm{H}_{2} \mathrm{~S}$ transform into $\mathrm{SO}_{42}$-on the surface of catalyst and this reaction can sulfate the $\mathrm{Al}_{2} \mathrm{O}_{3}$, thereby decreasing the basicity of catalysts.

To overcome the pernicious effect of $\mathrm{Al}_{2} \mathrm{O}_{3}$ that oxygen brings in, something that can remove oxygen must be introduced into catalyzer. Hydrodeoxygenation has been reported as a feasible way to remove the oxygen. Hydrodeoxygenation refers to the reaction of $\mathrm{O}_{2}$ and $\mathrm{H}_{2}$ generate into $\mathrm{H}_{2} \mathrm{O}$ to remove oxygen under the influence of deoxidizers. Cu-based deoxidizer has been widely used, but it has low deoxidization accuracy and oxygen capacity. Pd-based deoxidizer has wide operating temperature range and high deoxidization accuracy, but it is expensive and needs strict impurity in the raw material gas. Mn-based deoxidizer cannot be used in sulfur-containing atmosphere while coke oven gas contains a lot of sulfur. Ni-based deoxidizer has very high hydrodeoxygenation catalytic activity, however $\mathrm{Ni}$ can react with $\mathrm{CO}$ and coke oven gas has some CO. Mo-based deoxidizer has high hydrodeoxygenation catalytic activity, and it still work even in high temperature. In sulfur-containing atmosphere, Mo can generate $\mathrm{MoS}_{2}$ which has better hydrodeoxygenation catalytic activity, so Mo-based deoxidizer can add into middle temperature hydrolysis catalysts to avoid oxygen poisoning.

By considering the deoxidization ability of middle temperature COS hydrolysis catalysts added $\mathrm{MoO}_{3}$ and the change law of the deoxidization ability in different reaction conditions, some researches were investigated in this paper.

\section{Experimental}

\subsection{Preparation and Pre-Sulfidation of Catalysts}

The COS hydrolysis catalysts doped with $\mathrm{MoO}_{3}$ were prepared using impregnation method. Different mass ration of $\left(\mathrm{NH}_{4}\right) 6 \mathrm{Mo}_{7} \mathrm{O}_{24} \cdot 6 \mathrm{H}_{2} \mathrm{O}$ and $\mathrm{K}_{2} \mathrm{CO}_{3}$ were dissolved in some distilled water that accorded with the water absorption of 
supports. Then the corresponding mass of $\mathrm{Al}_{2} \mathrm{O}_{3}$ supports was added into the above solution. The mixture was maintained for $12 \mathrm{~h}$ at room temperature. Then put the mixture into the dying oven for $4 \mathrm{~h}$ at $120^{\circ} \mathrm{C}$. Finally put them into muffle furnace for calcination activation at $550^{\circ} \mathrm{C}$ for $5 \mathrm{~h}$.

\subsection{Pre-Sulfidation}

Catalyst was heated to $200^{\circ} \mathrm{C}$ in a $\mathrm{N}_{2}$ atmosphere, and then $\mathrm{H}_{2}$ and $\mathrm{H}_{2} \mathrm{~S}$ was inlet. $\mathrm{H}_{2}$ concentration was $50 \%-60 \%$ and $\mathrm{H}_{2} \mathrm{~S}$ concentration was $2000-2500$ $\mathrm{mgS} / \mathrm{m}^{3}$ with $\mathrm{N}_{2}$ balanced.

\subsection{Hydrodeoxygenation Tests}

Hydrodeoxygenation tests were performed in a fixed-bed micro-reactor. The experimental apparatus consists of gas inlet unit, reaction unit and detecting unit. Gases were controlled by rotameter and then introduced into a vertically quartz tube that was placed in a tube furnace. The inner diameter of the reaction quartz tube was $15 \mathrm{~mm} .10 \mathrm{ml}$ of sample was packed in the tube to a height of about $4.5 \mathrm{~cm}$, and then heated to the reaction temperature in a mixed gas flow. The mixed gas contains $\mathrm{H}_{2}, \mathrm{~N}_{2}, \mathrm{O}_{2}$ and $\mathrm{H}_{2} \mathrm{~S}$ or COS. The reaction temperature was range from $200^{\circ} \mathrm{C}$ to $300^{\circ} \mathrm{C}$.

\subsection{Determination of the Deoxidization Ability}

The concentration of $\mathrm{O}_{2}$ in inlet and outlet were determined through CG7900. The changes in the concentration of $\mathrm{O}_{2}$ in inlet and outlet indicate the deoxidization ability of the catalysts.

\section{Results and Discussion}

\subsection{The Pre-Sulfidation of Catalysts}

At the time of preparing catalysts, Mo was the form of ionic state in the impregnating solution firstly, then transformed into oxidation state when the catalysts were roasting and activating. However, only if molybdenum oxides were transformed into $\mathrm{MoS}_{2}$ can catalysts get more deoxidization ability. The reaction that occurs during the pre-sulfidation process is $\mathrm{MoO}_{3}+2 \mathrm{H}_{2} \mathrm{~S}+\mathrm{H}_{2}=\mathrm{MoS}_{2}+3 \mathrm{H}_{2} \mathrm{O}+$ $48.1 \mathrm{~kJ}$.

When the $\mathrm{H}_{2} \mathrm{~S}$ was at a low concentration, the time of pre-sulfidation would be grown. This will take more time for pre-sulfidation process in practical application. When the temperature of pre-sulfidation was too high, $\mathrm{H}_{2}$ would transform Mo oxides into Mo simple substance which could make the active component of hydrodeoxygenation loss. So, the concentration of $\mathrm{H}_{2} \mathrm{~S}$ in sulfidation gas was $2000-2500 \mathrm{mgS} / \mathrm{m}^{3}$ and the temperature was $200^{\circ} \mathrm{C}$.

\subsection{The Pre-Experiment of Catalysts Hydrodeoxygenation}

The change of the ratio of deoxidization for catalyst without Mo was shown in Figure 1 with the increase of time. As shown in Figure 1, the deoxidization ratio 


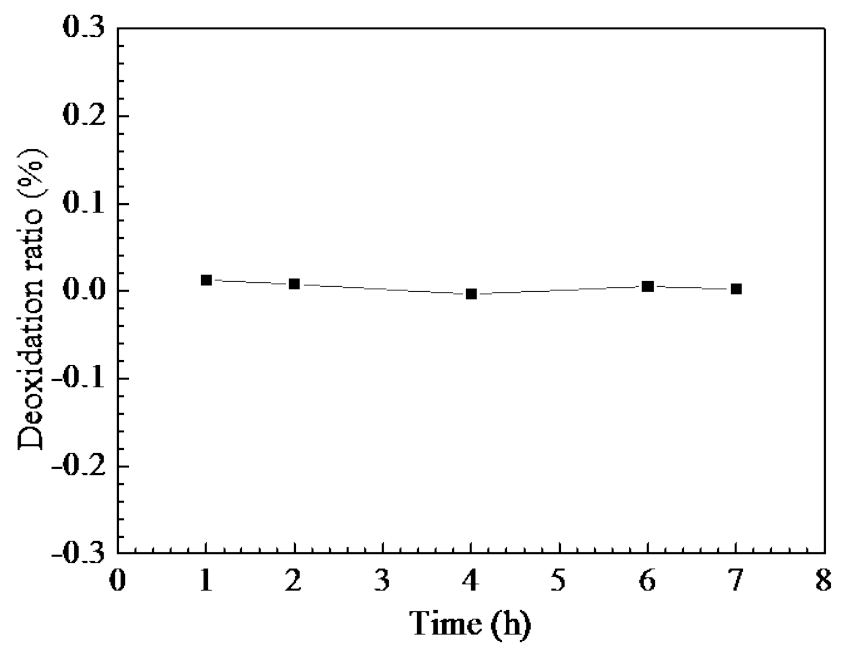

Figure 1. The change of the ratio of deoxidization for catalysts without Mo with the time increasing.

of the catalysts without Mo was nearly zero, and it could be proved that the catalysts without Mo did not have the ability of deoxidization and the oxidation of $\mathrm{H}_{2} \mathrm{~S}$ could not have effect on the determination of deoxidization ratio.

\subsection{The Effect of the Molybdenum Content on the Hydrolysis Ability of the Catalysts}

The change of the COS hydrolysis conversion for the catalysts was shown in Figure 2 with the increase of time. As shown in Figure 2, A referred to the catalyst without Mo doped, and B referred to the catalyst with $10 \mathrm{wt} . \%$ Mo doped, and $\mathrm{C}$ was the catalyst that doped with $10 \mathrm{wt} \%$ Mo after pre-sulfurized. The temperature of reactions were $300^{\circ} \mathrm{C}$, and the concentration of $\mathrm{H}_{2}$ was $20 \%$. The hydrolysis ability of the catalyst was decreased with the Mo doped in and this phenomenon was more significant when the catalyst was pre-sulfurized. Because the COS hydrolysis reaction was a base-catalysis, while the Mo doped in made the surface basicity decrease and decreased the hydrolysis ability eventually. And the pre-sulfidation made the surface basicity decrease further. It might be that after the pre-sulfidation the $\mathrm{S}_{2}$-occupied lots of surface space and made the COS difficult to combine with surface basic sites. Though the hydrolysis ability decreased with addition of Mo, it can make the catalyst have the ability of deoxidization to avoid the pernicious effect of $\mathrm{Al}_{2} \mathrm{O}_{3}$ that oxygen brought in.

\subsection{The Effect of Temperature and the Potassium Content on the Deoxidization Ability of the Catalysts}

Influences of temperature and the content of potassium on the ratio of deoxidization of catalyst were shown in Table 1 .

As shown in the Table 1, it can be concluded that the deoxidization ability raised with the increase of reaction temperature and the potassium content. From the thermodynamics, the hydrodeoxygenation reaction is an exothermic 


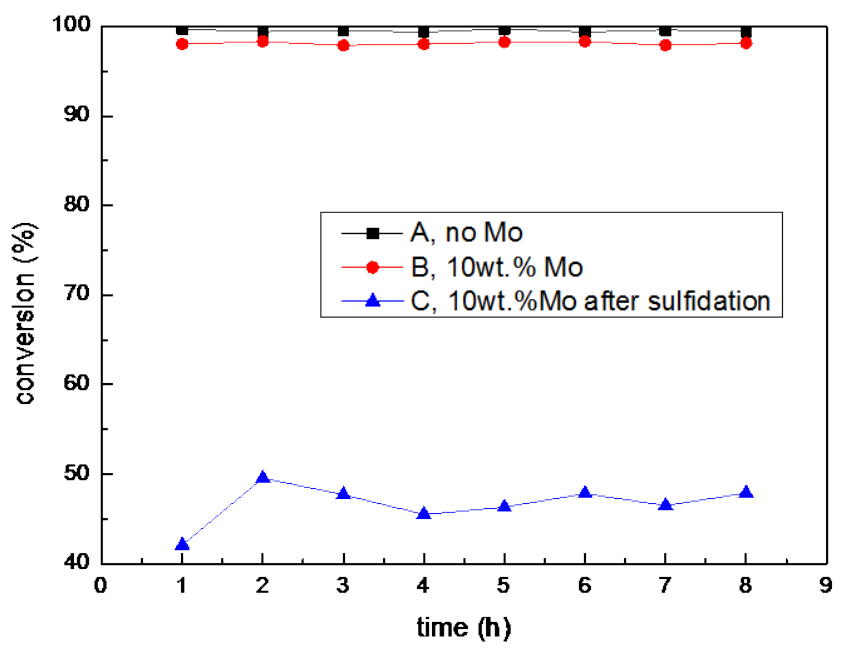

Figure 2. The change of the COS hydrolysis conversion ratio for catalysts in different forms of Mo-based with the time increasing.

Table 1. Influences of different Temperature and different potassium content on the ratio of deoxidization of catalyst.

\begin{tabular}{cccc}
\hline \multirow{2}{*}{ Content of potassium (\%) } & \multicolumn{3}{c}{ Ratio of deoxidization in different temperature (\%) } \\
\cline { 2 - 4 } & $200^{\circ} \mathrm{C}$ & $250^{\circ} \mathrm{C}$ & $300^{\circ} \mathrm{C}$ \\
\hline 5 & 1.12 & 2.58 & 3.14 \\
10 & 1.37 & 4.73 & 6.83 \\
15 & 9.67 & 30.39 & 50.41 \\
\hline
\end{tabular}

process, so deoxidization ability should be decreased with the increase of the reaction temperature. However, the actual deoxidization ratio showed the opposite tendency, this may be because that the hydrodeoxygenation reaction is away from the chemical equilibrium, catalyst improves the chemical reaction rate and the reaction rate increase with the temperature raising. As for potassium content, the $\mathrm{H}^{+}$in surface hydroxyl was replaced by $\mathrm{K}^{+}$with the potassium added in which could reduce the phase change of $\mathrm{Al}_{2} \mathrm{O}_{3}$ and accelerate electron transfer of activated oxygen and activated hydrogen. And $\mathrm{K}^{+}$not only could prompt $\mathrm{Mo}^{4+}$ into stable $\mathrm{Mo}^{5+}$ but also was the active center of oxidation-reduction reaction.

\subsection{The Effect of Sulfur-Containing Atmosphere the Deoxidization Ability of the Catalysts}

The change of the ratio of deoxidization for catalyst in different sulfur containing atmosphere was shown in Figure 3 with the increase of time. As shown in Figure 3, the $80,200,700,1100$ referred to the concentration of $\mathrm{H}_{2} \mathrm{~S}$, and that were $80 \mathrm{mgS} / \mathrm{m}^{3}, 200 \mathrm{mgS} / \mathrm{m}^{3}, 700 \mathrm{mgS} / \mathrm{m} 3,1100 \mathrm{mgS} / \mathrm{m}^{3}$. And the concentration of COS was $700 \mathrm{mgS} / \mathrm{m}^{3}$. The temperature of reactions were $300^{\circ} \mathrm{C}$, and the concentration of $\mathrm{H}_{2}$ was $20 \%$. The ratio of deoxidization did not significantly changed with the increased of the concentration of $\mathrm{H}_{2} \mathrm{~S}$, however in COS 


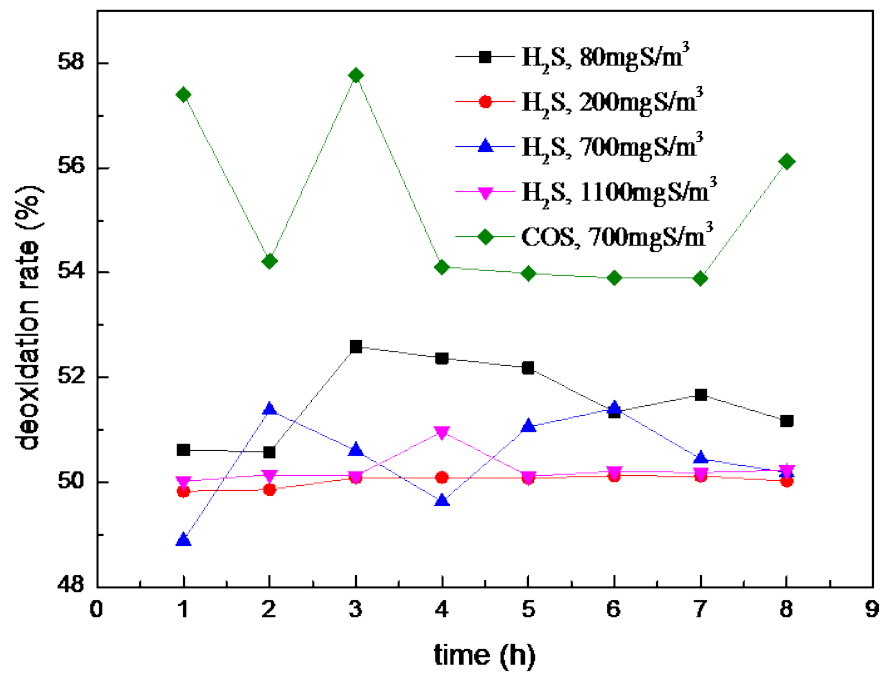

Figure 3. The ratio of deoxidization of catalysts in different sulfur containing atmosphere with the time increasing.

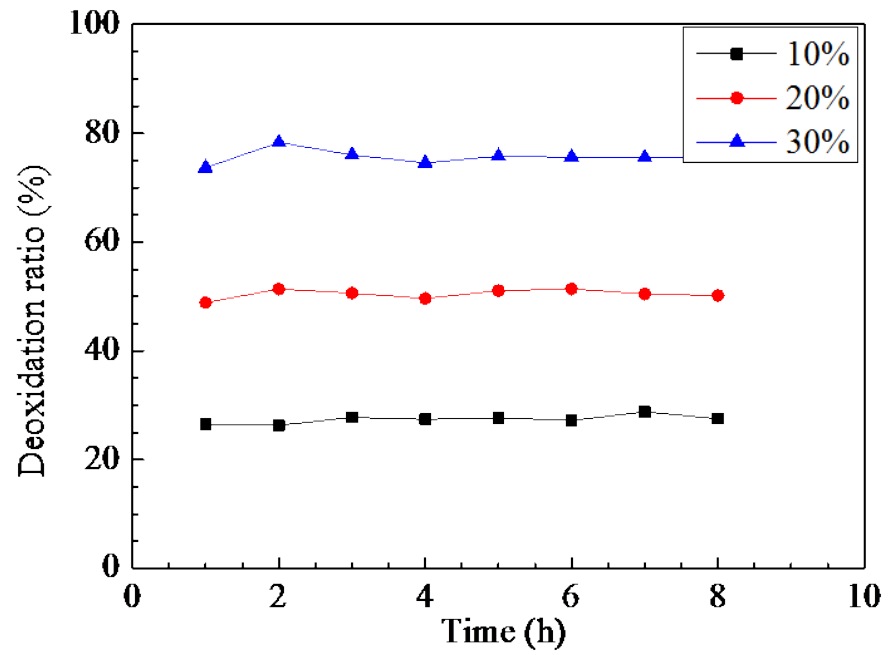

Figure 4. The ratio of deoxidization of catalysts in different concentration of $\mathrm{H}_{2}$.

atmosphere the ratio of deoxidization was raised a lot. That may be in COS atmosphere, the COS hydrolysis reaction can raise the concentration of surface $\mathrm{O}_{2}^{-}$in $\mathrm{Al}_{2} \mathrm{O}_{3}$ which is beneficial to the absorption of $\mathrm{H}_{2}$ and finally increase the ratio of deoxidization. In COS atmosphere the conversion of $\mathrm{COS}$ and $\mathrm{H}_{2} \mathrm{~S}$ may make the deoxidization unstable.

\subsection{The Effect of the Concentration of $\mathrm{H}_{2}$ on the Deoxidization Ability of the Catalysts}

The change of the ratio of deoxidization for catalyst in different concentration of $\mathrm{H}_{2}$ was shown in Figure 4 with the increase of time. As shown in Figure 4, the ratio of deoxidization of catalyst were raised with the increase of the concentration of $\mathrm{H}_{2}$. The ratio of deoxidization were nearly scaled up with concentration 
of $\mathrm{H}_{2}$, so it can be concluded that the controlling process of hydrodeoxygenation reaction was connected with $\mathrm{H}_{2}$ and that process might be a second order reaction.

\section{Conclusion}

At the process of catalyst deoxidization, the potassium can improve the deoxidization ability of the catalysts, and the improvement raised with the increase of potassium contents while at the process of hydrolysis the surface basicity decrease make the hydrolysis ability decrease. Catalyst improves the deoxidization rate and the deoxidization rate increase with the temperature raising. In the $\mathrm{H}_{2} \mathrm{~S}$ containing atmosphere the ratio of deoxidization did not change with the change of the concentration of $\mathrm{H}_{2} \mathrm{~S}$, however in the COS atmosphere the ratio of deoxidization raised a lot. The ratio of deoxidization scaled up with the increased of the concentration of $\mathrm{H}_{2}$ and that may be a second order reaction.

\section{Acknowledgements}

This work was supported by the National Natural Science Foundation of China (No. 20976116) and the Major Project of Science and Technology of Shanxi Province in 2016 (MJH2016-03).

\section{References}

[1] Wang, J., Liu, L., Han, L., Hu, Y., Chang, L. and Bao, W. (2013) Alumina-Supported Manganese Oxide Sorbent Prepared by Sub-Critical Water Impregnation for Hot Coal Gas Desulfurization. Fuel Processing Technology, 110, 235-241. https://doi.org/10.1016/j.fuproc.2012.12.020

[2] Cheah, S., Carpenter, D.L. and Magrinibair, K.A. (2009) Review of Mid- to High-Temperature Sulfur Sorbents for Desulfurization of Biomass- and Coal-Derived Syngas. Journal of Southwest Petroleum Institute, 23, 5291-5307. https://doi.org/10.1021/ef900714q

[3] Mathieu, Y., Tzanis, L., Soulard, M., Patarin, J., Vierling, M. and Molière, M. (2013) Adsorption of SOx by Oxide Materials: A Review. Fuel Processing Technology, 114, 81-100. https://doi.org/10.1016/j.fuproc.2013.03.019

[4] Yang, L., Dong, Y., Zhang, Y. and Xie, K. (2006) Present Situation and Development Prospect of Coke Oven Gas Utilization in China. Energy and Conservation, 1, 1-4.

[5] Whelan, M.E., Min, D.H. and Rhew, R.C. (2013) Salt Marsh Vegetation as a Carbonyl Sulfide (COS) Source to the Atmosphere. Atmospheric Environment, 73, 131-137. https://doi.org/10.1016/j.atmosenv.2013.02.048

[6] Ahmad, N., Husain, M.I., Kumar, R., et al. (2012) Comparative Kinetics of Corrosion Rate on Mild Steel in Various Citrus Juices. Ijsat Com, 2, 2221-8386.

[7] Jia, Z., Duan, X., Qin, P., et al. (2017) Disordered Atomic Packing Structure of Metallic Glass: Toward Ultrafast Hydroxyl Radicals Production Rate and Strong Electron Transfer Ability in Catalytic Performance. Advanced Functional Materials, 1702258. https://doi.org/10.1002/adfm.201702258

[8] Liang, S.X., Jia, Z., Zhang, W.C., et al. (2017) Rapid Malachite Green Degradation Using $\mathrm{Fe}_{73.5} \mathrm{Si}_{13.5} \mathrm{~B}_{9} \mathrm{Cu}_{1} \mathrm{Nb}_{3}$, Metallic Glass for Activation of Persulfate under UV-Vis 
Light. Materials \& Design, 119, 244-253.

https://doi.org/10.1016/j.matdes.2017.01.039

[9] Jia, Z., Kang, J., Zhang, W.C., et al. (2017) Surface Aging Behaviour of Fe-Based Amorphous Alloys as Catalysts during Heterogeneous Photo Fenton-Like Process for Water Treatment. Applied Catalysis B Environmental, 204, 537-547. https://doi.org/10.1016/j.apcatb.2016.12.001

[10] Jia, Z., Zhang, W.C., Wang, W.M., et al. (2016) Amorphous $\mathrm{Fe}_{78} \mathrm{Si}_{9} \mathrm{~B}_{13}$ Alloy: A Rapid and Reusable Photo-Enhanced Fenton-Like Catalyst in Degradation of Cibacron Brilliant Red 3B-A Dye under UV-Vis Light. Applied Catalysis B Environmental, 192, 46-56. https://doi.org/10.1016/j.apcatb.2016.03.048

[11] Liu, Y. and He, H. (2009) Experimental and Theoretical Study of Hydrogen Thiocarbonate for Heterogeneous Reaction of Carbonyl Sulfide on Magnesium Oxide. Journal of Physical Chemistry A, 113, 3387-3394. https://doi.org/10.1021/jp809887c

[12] Ju, S.G., Zhao, Y.S., Fan, H.L., Liang, L.T., Shen, F. and Miao, M.Q. (2013) Desulfurization Behavior of Zinc Oxide Based Sorbent Modified by the Combination of $\mathrm{Al}_{2} \mathrm{O}_{3}$ and $\mathrm{K}_{2} \mathrm{CO}_{3}$. Fuel, 108, 80-84. https://doi.org/10.1016/j.fuel.2011.04.011

[13] Liu, J., Liu, Y., Li, X., Yu, Y. and Hong, H. (2007) Oxygen Poisoning Mechanism of Catalytic Hydrolysis of OCS over $\mathrm{Al}_{2} \mathrm{O}_{3}$ at Room Temperature. Acta Physico-Chimica Sinica, 23, 997-1002. https://doi.org/10.1016/S1872-1508(07)60054-0 